\title{
Armazenamento do crambe em diferentes embalagens e ambientes: Parte II - Qualidade química
}

Juliana R. Donadon ${ }^{1}$, Jaqueline F. V. Bessa ${ }^{2}$, Osvaldo Resende ${ }^{3}$, Carlos F. de S. Castro ${ }^{4}$, Rosa M. V. Alves ${ }^{5}$ \& Eduardo V. Silveira ${ }^{6}$

\section{Palavras-chave:}

qualidade da semente

teor de óleo

proteína bruta

Crambe abyssinica

\begin{abstract}
R E S U M O
Objetivou-se, neste trabalho, avaliar o efeito de diferentes embalagens, ambientes e do tempo de armazenamento na qualidade de sementes de crambe. O crambe, com teor de água de 4,63\% (b.u.), foi embalado em garrafas de polietileno de alta densidade (PEAD), em garrafas reutilizadas de polietileno tereftalato (PET) e em embalagens laminadas as quais foram armazenadas nos ambientes: refrigerado a $10 \pm 1,19^{\circ} \mathrm{C}$ e $34,84 \pm 4,09 \%$ de umidade relativa (UR) e natural a $24,81 \pm 1,82^{\circ} \mathrm{C}$ e $54,93 \pm 12,77 \%$ de umidade relativa (AN). Avaliaram-se, durante nove meses, o teor de óleo e de proteína bruta, os índices de acidez, peróxido e iodo, $\mathrm{pH}$ e acidez em álcool solúvel. As sementes acondicionadas em embalagem laminada no $\mathrm{AN}$ apresentaram maior teor de proteína bruta no $3^{\circ}$ mês e as em $\mathrm{AR}$, maiores índices de peróxido, nos $3^{\circ}$ e $6^{\circ}$ meses. Em AR, as sementes em embalagens de PEAD apresentaram menor acidez em álcool solúvel. Os teores de proteína bruta e de óleo diminuíram durante o armazenamento, o índice de peróxido e o $\mathrm{pH}$ aumentaram e o índice de iodo apresentou variação nos valores. No final do armazenamento os valores de acidez em álcool solúvel eram semelhantes aos do início. O índice de acidez não sofreu interferência das variáveis estudadas.
\end{abstract}

\section{Key words:}

seed quality

oil content

crude protein

Crambe abyssinica

\section{Storage of crambe seeds in different containers and environments: Part II - Chemical quality}

\begin{abstract}
A B S T R A C T
The aim of this study was to evaluate the effect of different packaging, environment and storage time on the chemical quality of crambe seeds. Crambe seeds, with a water content of $4.63 \%$ (dry basis), were packed into high density polyethylene (HDPE), reused polyethylene terephthalate (PET) bottles and laminated packages, which were stored in two different environments: refrigerated air (RA) at $10 \pm 1.19^{\circ} \mathrm{C}$ and $34.84 \pm 4.09 \%$ relative humidity $(\mathrm{RH})$ and natural air (AN) at $24.81 \pm 1.82^{\circ} \mathrm{C}$ and $54.93 \pm 12.77 \% \mathrm{RH}$. For nine months, the oil and crude protein content, acidity index, peroxide and iodine level, $\mathrm{pH}$, and alcohol-soluble acidity were evaluated. Seeds in laminated packages stored in AN showed higher crude protein content after $3^{\text {rd }}$ month, and in AR, there were higher levels of peroxide after $3^{\text {rd }}$ and $6^{\text {th }}$ months. In AR, the seeds in HDPE packaging showed lower alcohol-soluble acidity. Crude protein and oil content decreased during storage, peroxide level and $\mathrm{pH}$ increased and iodine level varied. At the end of storage, the alcohol-soluble acidity returned to base line values. The acidity level was not affected by the changes in the variables studied.
\end{abstract}

Protocolo 045-2014 - 10/02/2014 • Aprovado em 10/10/2014 • Publicado em 26/01/2015

${ }^{1}$ UTASP-CCBS/UFMS. Campo Grande, MS. E-mail: julianadonadon@yahoo.com.br

${ }^{2}$ LPCPV/IF Goiano. Rio Verde, GO. E-mail: jaqueline@agricola.eng.br (Autora correspondente)

${ }^{3}$ LPCPV/IF Goiano. Rio Verde, GO. E-mail: osvresende@yahoo.com.br

${ }^{4}$ QuiTec/IF Goiano. Rio Verde, GO. E-mail: cfrederico.rv@ifgoiano.edu.br

${ }^{5}$ ITAL. Campinas, SP. E-mail: rosa@ital.sp.gov.br

${ }^{6}$ QuiTec/IF Goiano. Rio Verde, GO. E-mail: duardimrv@hotmail.com 


\section{INTRODUÇÃo}

O Crambe abyssinica é uma espécie nativa do Mediterrâneo, que se vem destacando pelo interesse industrial do óleo extraído de suas sementes que está sendo utilizado recentemente para a produção de biodiesel (Carneiro et al., 2009). Nos últimos anos é considerada uma das principais culturas para a produção deste combustível, com testes que comprovam a boa qualidade do óleo. A produtividade dessa cultura varia de 1.000 a 1.500 $\mathrm{kg} \mathrm{ha}^{-1}$ (Pitol, 2008).

Segundo Rosseto et al. (2012) é possível extrair cerca de $38 \%$ de óleo de sementes de crambe, dependendo do solvente utilizado.

O processo de deterioração das sementes é inevitável e ocorre após a maturidade fisiológica cuja consequência final e mais drástica é a perda da viabilidade (Marcos Filho, 2005).

Os sintomas fisiológicos mais evidentes decorrentes da deterioração das sementes são aparentes durante a germinação e o desenvolvimento inicial das plântulas. Outra manifestação da deterioração de sementes durante o armazenamento tem sido a desestruturação do sistema de membranas como consequência do ataque aos seus constituintes químicos pelos radicais livres. A instabilidade química dos lipídeos constitui um dos fatores preponderantes para a queda do desempenho das sementes de várias espécies, especialmente das oleaginosas (José et al., 2010).

Sementes oleaginosas podem sofrer deterioração ao longo do armazenamento com formação de ácidos graxos livres resultantes da hidrólise da gordura; portanto, a análise da acidez graxa permite, além de quantificar o processo deteriorativo, acusá-lo ainda nos estágios iniciais (Biaggioni \& Barros, 2006).

O elevado teor de óleo na composição das sementes resulta em uma estabilidade menor das moléculas as quais se degradam com maior velocidade culminando em perda da viabilidade das sementes (Bewley \& Black, 1994) ocasionada pela deterioração.

Marcos Filho (2005) relaciona o uso de embalagens e o tipo de permeabilidade ao vapor d'água com a manutenção da qualidade de sementes visto que permite maiores ou menores trocas de vapor entre as sementes e a atmosfera do ambiente em que estão armazenadas. Nos últimos anos várias tecnologias têm sido empregadas para a manutenção da qualidade durante o armazenamento de sementes, dentre elas o uso de diferentes embalagens (Oliveira et al., 2009; Silva et al., 2010).

Objetivou-se então, neste trabalho, avaliar o efeito de diferentes embalagens, ambientes e do tempo de armazenamento na qualidade de sementes de crambe.

\section{Material e Métodos}

O experimento foi realizado no Instituto Federal de Educação, Ciência e Tecnologia Goiano - Câmpus Rio Verde (IF Goiano), no Laboratório de Pós-Colheita de Produtos Vegetais, Laboratório de Química Tecnológica e Laboratório de Nutrição Animal.

Foram utilizadas sementes de crambe (Crambe abyssinica Hochst) cultivadas na safra de 2012, no município de Jataí -
GO, a $17^{\circ} 53^{\prime} 36,31^{\prime \prime}$ de latitude (S) e $51^{\circ} 42^{\prime} 52,25^{\prime \prime}$ de longitude (O).

As sementes de crambe foram colhidas mecanicamente com teor de água de aproximadamente $10 \%$ (b.u.) e em seguida encaminhadas para a realização da limpeza e secagem; durante a limpeza as impurezas foram removidas como torrões de terra, palhas e outras matérias estranhas.

A secagem das sementes foi realizada pelo método artificial com ar natural em terreiro de concreto até que o teor de água atingisse 4,6 \% (b.u.) para o armazenamento seguro desta oleaginosa. O teor de água foi determinado por gravimetria utilizando-se a estufa Marconi ${ }^{\circledast}$ MA - 035, com circulação de ar forçado a $105 \pm 1{ }^{\circ} \mathrm{C}$, até massa constante, em três repetições.

Depois da secagem as sementes foram acondicionadas em garrafas de polietileno de alta densidade (PEAD) com capacidade de 1,0 L; em garrafas reutilizadas de polietileno tereftalato (PET) cuja embalagem foi higienizada com água e detergente neutro e depois sanitizada com solução de 200 $\mathrm{mL} \mathrm{L}^{-1}$ de cloro ativo apresentando capacidade de 2,0 L; a taxa de transmissão ao vapor d'água (a $38^{\circ} \mathrm{C}$ e $90 \%$ UR) das embalagens apresentou $0,02 \mathrm{~g}$ de água embalagem ${ }^{-1}$ $\mathrm{d}^{-1}$ e $0,23 \mathrm{~g}$ de água embalagem ${ }^{-1} \mathrm{~d}^{-1}$, respectivamente. A embalagem flexível com capacidade de $1,0 \mathrm{~kg}$, laminada com a seguinte estrutura: folha de PET + folha de alumínio (Al) + folha de polietileno de baixa densidade (PEBD) com taxa de permeabilidade ao vapor d'água (TPVA) inferior a $0,01 \mathrm{~g}$ água $\mathrm{m}^{-2} \mathrm{~d}^{-1}$ a $38{ }^{\circ} \mathrm{C}$ e $90 \%$ UR.

As embalagens foram acondicionadas em ambiente refrigerado (AR) a $10{ }^{\circ} \mathrm{C}$, em estufa $\mathrm{BOD}$ e em ambiente natural (AN). A temperatura e a umidade relativa (UR) dos ambientes de armazenamento foram monitoradas por meio de um termohigrógrafo Novus ${ }^{\circledast} \log$ box RHT-LCD.

As sementes foram armazenadas no período de julho de 2012 a abril de 2013; nos diferentes ambientes amostras foram retiradas aos 0, 3, 6 e 9 meses, em triplicata e ao acaso, para a realização das avaliações de proteína bruta, teor de óleo, pH e acidez em álcool solúvel; do óleo extraído das sementes foram avaliados os índices de acidez, de peróxidos e de iodo.

O teor de proteína bruta foi determinado pelo método descrito por Silva \& Queiroz (2002), que consiste na determinação do nitrogênio total; para converter o resultado em proteína bruta foi utilizado o fator 6,25. Os resultados foram expressos em \%, em relação à massa da amostra seca.

O óleo foi extraído de acordo com o método descrito pelo IAL (2008). Cerca de $100 \mathrm{~g}$ de crambe foram triturados, divididos em quatro porções homogêneas ( 4 x $25 \mathrm{~g}$ ) e transferidos para um aparelho de extração tipo Soxhlet. Foram adicionados $300 \mathrm{~mL}$ de hexano e mantidos sob aquecimento em refluxo constante, durante $8 \mathrm{~h}$. O solvente foi retirado sob pressão reduzida em um evaporador rotativo Fisatom modelo 801. O teor de óleo foi calculado por meio da soma da massa de óleo multiplicado por 100 e dividido pela massa seca das sementes trituradas.

Para determinar o índice de acidez utilizou-se o método descrito pelo IAL (2008) através da Eq. 1:

$$
\mathrm{IA}=\frac{\mathrm{V} \times \mathrm{M} \times 56,1}{\mathrm{~m}}
$$


em que:

IA - índice de acidez, mg KOH g-1 óleo

$\mathrm{V}$ - volume da solução padronizada de $\mathrm{KOH}, \mathrm{mL}$

M - molaridade da solução de $\mathrm{KOH}$

56,1 - massa molecular do $\mathrm{KOH}$

m - massa da amostra de óleo, g

A solução de $\mathrm{KOH}$ foi padronizada utilizando-se o biftalato de potássio seco, como padrão primário.

Com vista à determinação do índice de peróxidos, utilizouse o método descrito pelo IAL (2008) calculado conforme a Eq. 2:

$$
\mathrm{IP}=\frac{\mathrm{V} \times \mathrm{M} \times 1000}{\mathrm{~m}}
$$

em que:

IP - índice de peróxidos, $\mathrm{mEq} \mathrm{kg}^{-1}$ de amostra

$\mathrm{V}$ - volume de $\mathrm{Na}_{2} \mathrm{~S}_{2} \mathrm{O}_{3}$ gasto na titulação da amostra, $\mathrm{mL}$

$\mathrm{M}$ - molaridade da solução de $\mathrm{Na}_{2} \mathrm{~S}_{2} \mathrm{O}_{3}$

m - massa da amostra, g

A solução de tiossulfato de sódio foi padronizada utilizando-se dicromato de potássio, em meio ácido.

$\mathrm{O}$ índice de iodo foi determinado pelo método descrito pelo IAL (2008) por meio da Eq. 3.

$$
\mathrm{II}=\frac{\mathrm{V} \times \mathrm{C} \times 126,9}{\mathrm{~m}} \times 100
$$

em que:

II - Índice de Iodo, g I $100 \mathrm{~g}^{-1}$ óleo

$\mathrm{V}$ - volume gasto do branco menos o volume do titulante, $\mathrm{L}$

C - concentração do titulante, $\mathrm{mol} \mathrm{L}^{-1}$

126,9 - massa molecular do iodo

m - massa da amostra, kg

A solução de tiossulfato de sódio foi padronizada utilizando-se dicromato de potássio em meio ácido.

$\mathrm{O} \mathrm{pH}$ da farinha das sementes foi determinado por meio de potenciômetro Del Lab, modelo DLA - PH, calibrado com tampão pH 7,0 e pH 4,0 (AOAC, 1997).

A acidez em álcool solúvel da farinha das sementes, expressa em mL de solução normal de $\mathrm{NaOH} 100 \mathrm{~g}^{-1}$ foi determinada por meio da titulação da amostra com hidróxido de sódio 0,01 $\mathrm{N}$, até coloração rósea persistente (IAL, 2008).

Todos os reagentes utilizados são de grau analítico p.a. O hidróxido de sódio, o hidróxido de potássio e amido são da marca Synth enquanto a solução de Hanus, o dicromato de potássio, o ácido acético glacial, o iodeto de potássio, o tiossulfato de potássio e o hexano são da marca cinética, o éter etílico, álcool etílico e clorofórmio da Dinâmica.

O experimento foi realizado utilizando-se um delineamento inteiramente casualizado (DIC) em esquema fatorial triplo ( $3 \times 2 \times 4)$, sendo três tipos de embalagem (laminada, PET e PEAD), dois ambientes de armazenamento (AR e AN) e quatro tempos (0, 3, 6 e 9 meses); para as avaliações amostras foram tomadas em triplicata e ao acaso; os dados foram analisados por meio de análise de variância e regressão; já para o fator qualitativo, as médias foram comparadas utilizando-se o teste de Tukey e se adotando o nível de 0,05 de significância; para o fator quantitativo os modelos foram selecionados com base na significância da equação, pelo teste $F$, na significância dos coeficientes de regressão adotando-se o nível de 0,05 de significância e no coeficiente de determinação $\left(R^{2}\right.$ para regressão polinomial).

\section{Resultados e Discussão}

Análises realizadas em microscópio eletrônico de varredura, por Donadon et al. (2013), revelaram que o grão de crambe é constituído por pericarpo pouco espesso e semente. Neste trabalho se optou por designar o crambe como semente. Outros autores também nomearam grãos de crambe como sementes tais como Souza et al. (2009) e Faria et al. (2012), embora outros como frutos de crambe (Costa et al., 2012a; 2012b).

A média geral de temperatura e o UR no $A R$, foram de $10,19 \pm 1,19^{\circ} \mathrm{C}$ e $34,84 \pm 4,09 \%$ e no $\mathrm{AN}$, de $24,81 \pm 1,82^{\circ} \mathrm{C}$ e $54,93 \pm 12,77 \%$, respectivamente. Durante o armazenamento em ambiente refrigerado a umidade relativa mais baixa ocorreu no mês de outubro de $2012(29,82 \pm 1,37 \%)$ e a mais elevada em agosto do mesmo ano $(40,22 \pm 1,53 \%)$, enquanto em ambiente natural nos meses de outubro (30,04 $\pm 6,60 \%)$ e março de 2012 $(72,62 \pm 8,63 \%)$, respectivamente.

Na Figura 1 se apresentam as médias do teor de proteína bruta e do teor de óleo das sementes de crambe ao longo do armazenamento.

Verifica-se, na Figura 1A, que as sementes das diferentes embalagens não diferiram entre si quanto ao teor de proteína bruta, exceto no terceiro mês de armazenamento quando na embalagem laminada as sementes apresentaram maior teor de proteína. Os valores de proteína bruta não diferiram nos diferentes ambientes de armazenamento, mas se observou efeito do tempo apresentando uma queda gradativa nos valores durante o armazenamento. Nas embalagens PET e PEAD a proteína das sementes apresentou uma redução linear de 0,17 e $0,25 \%$ por mês, respectivamente, enquanto na embalagem laminada os dados se ajustaram a um modelo quadrático com máximo teor de proteína a 1,22 mês de armazenamento $(22,68 \%)$. Os valores de proteína bruta encontrados são semelhantes aos obtidos por Souza et al. (2009) porém inferiores aos encontrados por Goes et al. (2010). Os resultados indicam que durante o armazenamento ocorreu degradação das proteínas. Eichelberger et al. (2002) verificaram que durante o armazenamento de sementes de azevém (Lolium multiflorum Lam.) houve degradação das proteínas através da solubilização; no entanto, os requerimentos energéticos para respiração de manutenção dos tecidos foram pequenos. Esses autores ainda observaram correlação positiva entre os teores de proteína solúvel e a germinação, durante o armazenamento, por quatro e oito meses.

O teor de óleo extraído das sementes de crambe foi, em média, de $36,42 \%$. Este valor está coerente com os obtidos por Rosseto et al. (2012), avaliando o efeito da secagem na extração de óleo de crambe.

Somente o fator tempo influenciou no teor de óleo das sementes; nota-se, na Figura 1B, que o teor de óleo reduziu linearmente ao longo do armazenamento. Para cada mês 

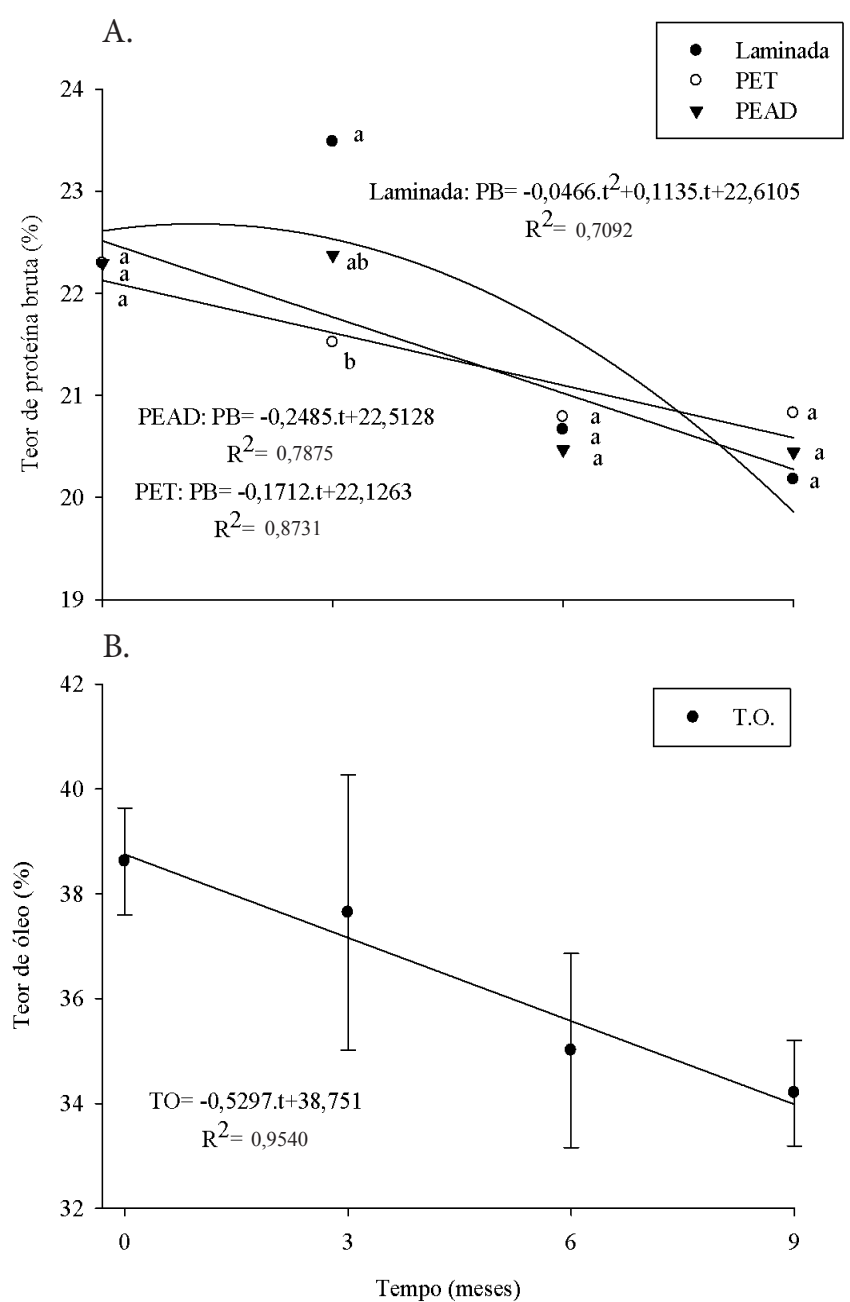

Letras iguais no mesmo tempo não diferem entre si pelo teste de Tukey a 0,05 de significância; PET - polietileno tereftalato; PEAD - polietileno de alta densidade

Figura 1. Teor de proteína bruta das sementes de crambe (A) acondicionadas em diferentes embalagens durante o armazenamento e teor de óleo (B) durante o armazenamento

de armazenamento houve uma redução de $0,53 \%$ no teor de óleo das sementes de crambe. Alencar et al. (2009) também observaram, avaliando a qualidade de grãos de soja armazenados em diferentes condições, queda no teor de óleo nos grãos com teor de água de $14,8 \%$ (b.u.) nas temperaturas de 30 e $40^{\circ} \mathrm{C}$, ao longo de seis meses.

Rupollo et al. (2004) afirmaram que durante o armazenamento as sementes se deterioram por processos bioquímicos, como a respiração ou processos oxidativos resultando na diminuição de lipídeos, ou seja, ocorre a hidrólise, o que explica a redução no teor de óleo das sementes de crambe ao longo do armazenamento. Freo et al. (2012) também constataram redução no teor de lipídeos em grãos de trigo durante o armazenamento.

O índice de acidez do óleo o para o crambe foi $1,03 \mathrm{mg}$ de $\mathrm{KOH} g$ de óleo-1 ${ }^{-1}$ superior ao encontrado por Silva et al. (2013) $\left(0,43\right.$ a 0,61 mg KOH g amostra $\left.{ }^{-1}\right)$. Apesar do teor de óleo diminuir em função do tempo, o índice de acidez não sofreu interferência do tempo de armazenamento nem das embalagens e ambientes. De acordo com Freo et al. (2012) a redução de lipídeos e o aumento de ácidos graxos livres estão diretamente correlacionados com a velocidade e intensidade do processo de deterioração dos grãos e das sementes. A decomposição dos glicerídeos é acelerada pelo aquecimento e pela luz enquanto a rancidez é quase sempre acompanhada pela formação de ácido graxo livre (Farhoosh et al., 2009).

Biaggioni \& Barros (2006) verificaram a correlação entre o teste de acidez graxa em sementes de arroz e as classes de vigor em sementes e constataram que esse teste se mostrou exequível para avaliar o vigor das sementes. Como a acidez do óleo não se alterou ao longo do tempo, pode-se deduzir, analisando isoladamente este parâmetro, que as sementes se mantiveram vigorosas.

O índice de peróxido sofreu influência do ambiente e do tempo de armazenamento, enquanto o índice de iodo do tempo, tendo as médias apresentadas na Figura 2.

Na Figura 2A estão apresentados os valores do índice de peróxido em função do tempo de armazenamento nos diferentes ambientes. Verifica-se que houve diferença entre os ambientes de armazenamento nos $3^{\circ}$ e $6^{\circ}$ meses, com as sementes armazenadas no AR apresentando maiores índices.

$\mathrm{O}$ índice de peróxido teve um aumento linear em função do tempo sinalizando a degradação e a oxidação do óleo. Para cada mês de armazenamento verificou-se aumento de $0,71 \%$ no AR e $0,64 \%$ no AN; este comportamento também foi observado por Alencar et al. (2010) estudando a influência das condições de armazenamento da soja sobre a qualidade do óleo bruto.

Faroni et al. (2009) obtiveram valores similares aos encontrados nas sementes de crambe para índice de peróxido,

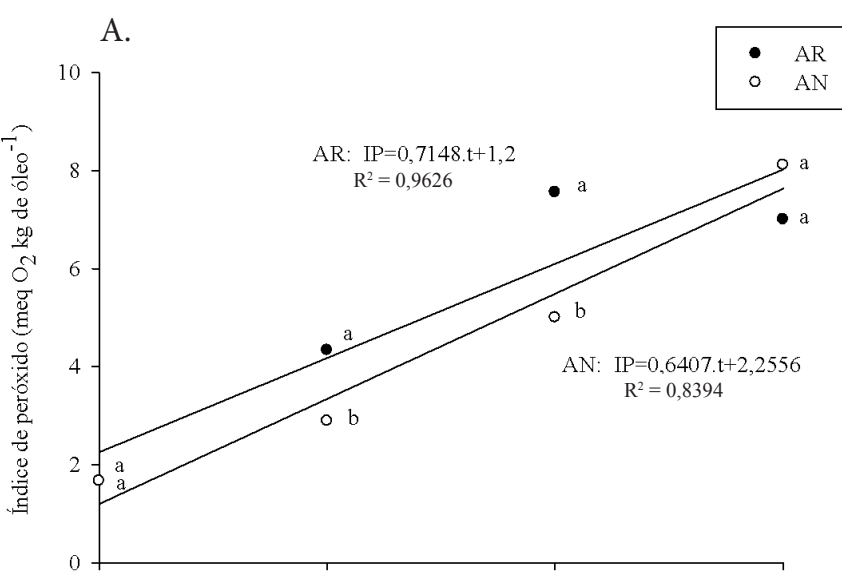

B.

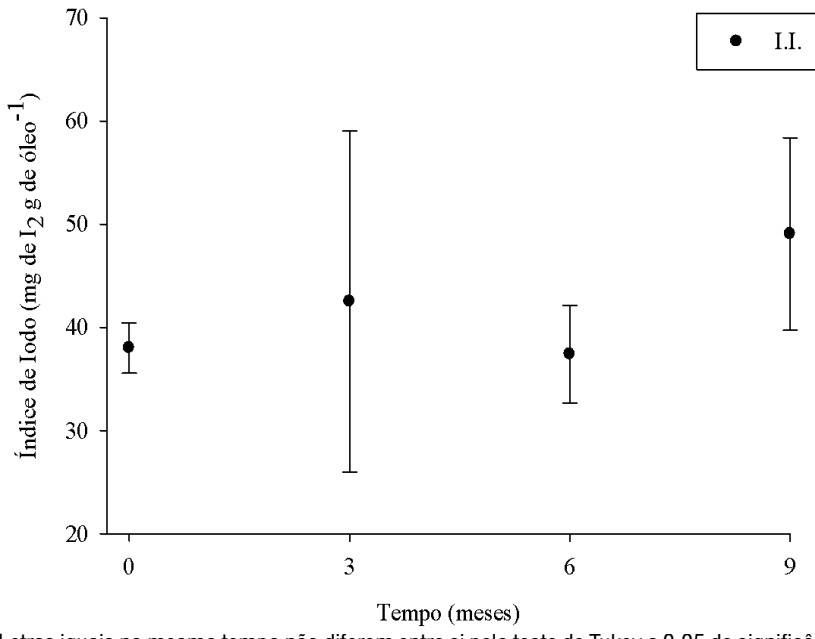

Letras iguais no mesmo tempo não diferem entre si pelo teste de Tukey a 0,05 de significância; AR - umidade relativa; AN - ambiente natural

Figura 2. Índice de peróxido do óleo (IP) das sementes de crambe armazenadas em diferentes ambientes (A) e índice de iodo (I.I.) do óleo durante o armazenamento (B) 
entre 4,5 e 9,0 $\mathrm{mEq} \mathrm{kg}^{-1} \mathrm{em}$ sementes de soja úmidas e entre 3,0 e $6,0 \mathrm{mEq} \mathrm{kg}^{-1} \mathrm{em}$ secas, valores permitidos dentro dos limites estabelecidos em regulamentos para comercialização da soja (Faroni et al., 2009).

Observa-se, na Figura 2B, que o índice de iodo variou ao longo do armazenamento sendo influenciado apenas pelo fator tempo sem apresentar tendência clara variando entre 37,8 e 48,9 mg de $\mathrm{I}_{2} \mathrm{~g} \mathrm{de} \mathrm{óleo}^{-1}$. Os dados não se ajustaram a modelo matemático algum.

O índice de iodo proporciona uma medida do grau de insaturação das gorduras extraídas por éter. Por esta razão, quanto maior for a insaturação de um ácido graxo maior também será sua capacidade de absorção de iodo (Nozaki et al., 2012).

Ribeiro et al. (2010) obtiveram, avaliando os efeitos do armazenamento sobre o óleo de pinhão-manso que possuíam, inicialmente, índices de acidez, de peróxido e de iodo de: 2,4 mg KOH g amostra $^{-1}$; 99,0 $\mathrm{g}$ (100 g amostra $)^{-1}$ e de 12,0 mEq $(\mathrm{kg} \text { amostra })^{-1}$, respectivamente e no final de oito meses de armazenamento médias de $3,3 \mathrm{mg} \mathrm{KOH}$ ( $\mathrm{g}$ amostra $)^{-1} ; 130,0 \mathrm{~g}$ (100 $\left.\mathrm{g}_{\text {amostra }}\right)^{-1}$ e 17,0 mEq (kg amostra $)^{-1}$ respectivamente, valores superiores aos encontrados no presente trabalho para o óleo de crambe evidenciando que o óleo das sementes de crambe apresenta melhor qualidade ao longo do armazenamento em comparação com o de pinhão-manso.

$\mathrm{Na}$ Figura 3 se apresentam as médias de $\mathrm{pH}$ e acidez em álcool solúvel das sementes de crambe; para o $\mathrm{pH}$ ocorreu efeito do ambiente e do tempo enquanto para a variável acidez em álcool solúvel houve efeito do tempo e interação significativa embalagem $x$ ambiente (Tabela 1).

Verifica-se, na Figura 3A, que os valores de $\mathrm{pH}$ das sementes de crambe armazenadas em AR diferiram do AN tão somente no $6^{\circ}$ mês de armazenamento; as embalagens não influenciaram nos valores de $\mathrm{pH}$. $\mathrm{O} \mathrm{pH}$ aumentou linearmente durante o tempo independentemente do ambiente de armazenamento indicando que as sementes se tornaram menos ácidas; para cada mês de armazenamento observou-se um aumento no valor de $\mathrm{pH}$ de 0,045 para as sementes armazenados em AR e 0,041 em AN; de acordo com Monteiro et al. (2008), o pH varia segundo o tipo de armazenamento, ou seja, de conformidade com a atmosfera, a temperatura e a umidade relativa do ar.

A média de $\mathrm{pH}$ das sementes de crambe foi de 5,96 a 6,39 ao longo do armazenamento independentemente das condições, valores esses dentro da faixa de $\mathrm{pH}$ ácido porém próximos da neutralidade.

Na Figura 3B estão apresentadas as médias da variável acidez em álcool solúvel. Não foi possível ajustar um modelo matemático aos dados experimentais mas se verifica que a acidez foi mais elevada só no sexto mês mas após nove meses os valores eram semelhantes aos do início do armazenamento.

O crambe possui elevado teor de óleo e proteína (Donadon et al., 2013), e em sementes deterioradas esses componentes podem sofrer modificações elevando a acidez da farinha, o que não foi observado após 3 e 9 meses de armazenamento.

Belmiro et al. (2010) verificaram aumento nos teores de acidez titulável em sementes de abóbora durante o armazenamento em diferentes teores de água. Atribuíram, possivelmente, à alteração nos lipídeos contidos nos grãos de abóbora, provocando a formação de ácidos graxos livres.



Letras iguais ao mesmo tempo não diferem entre si pelo teste de Tukey a 0,05 de significância; AR - ambiente refrigerado; AN - ambiente natural

Figura 3. Valores de $\mathrm{pH}$ das sementes de crambe armazenadas em diferentes ambientes (A) e de acidez em álcool solúvel (B) durante o armazenamento

Tabela 1. Médias da acidez em álcool solúvel ( $\mathrm{mL}$ de solução normal de $\mathrm{NaOH} 100 \mathrm{~g}^{-1}$ ) das sementes de crambe nas diferentes condições de armazenamento

\begin{tabular}{ccc}
\hline \multirow{2}{*}{ Embalagens } & \multicolumn{2}{c}{ Ambientes } \\
\cline { 2 - 3 } Laminada & AR & AN \\
PET & $0,73 \mathrm{abA}$ & $0,77 \mathrm{aA}$ \\
PEAD & $0,71 \mathrm{bB}$ & $0,78 \mathrm{aA}$ \\
\hline
\end{tabular}

AN - Ambiente Natural; AR - Ambiente Refrigerado. Letras minúsculas iguais na coluna não diferem entre si. Letras maiúsculas iguais na linha diferem entre si

Durante o armazenamento em $\mathrm{AN}$ as sementes armazenadas nas diferentes embalagens não diferiram entre si quanto aos teores de acidez em álcool solúvel mas quando armazenadas em AR, as armazenadas em embalagens de PEAD apresentaram maior acidez em álcool solúvel e as em embalagens PET, menor acidez. Tornou-se patente o fato de que as embalagens PET permitiram maior alteração no teor de água das sementes durante o armazenamento nos dois ambientes, indicando que em AR a alteração do teor de água não influenciou a qualidade do crambe.

Os modelos ajustados aos dados experimentais de teor de proteína, teor de óleo, índice de peróxido, índice de iodo e $\mathrm{pH}$ do crambe indicaram coeficiente de determinação entre 78,95 
e $96,26 \%$, representando satisfatoriamente a evolução desses parâmetros, ao longo do tempo.

\section{Conclusões}

1. O armazenamento das sementes de crambe ao longo de nove meses reduziu o teor de proteína e do óleo mas se mostrou viável, independentemente do ambiente, preservando as características químicas do óleo extraído.

2. As embalagens pouco interferiram na qualidade das sementes de crambe, a laminada preserva maiores valores de proteína bruta e a PET menor acidez em álcool solúvel em ambiente refrigerado.

\section{Agradecimentos}

À FAPEG, à CAPES, ao CNPq (processo 480435/ 2011-1), à FINEP e ao IF Goiano, pelo apoio financeiro; à CARAMURU e ao ITAL, pela parceria.

\section{Literatura Citada}

Alencar, E. R.; Faroni, L. R. D.; Lacerda Filho, A. F.; Peternelli, L. A.; Costa, A. R. Qualidade dos grãos de soja armazenados em diferentes condições. Revista Brasileira de Engenharia Agrícola e Ambiental, v.13, p.606-613, 2009. http://dx.doi.org/10.1590/ S1415-43662009000500014

Alencar, E. R.; Faroni, L. R. D.; Peternelli, L. A.; Silva, M. T. C.; Costa, A. R. Influence of soybean storage conditions on crude oil quality. Revista Brasileira de EngenhariaAgrícola e Ambiental, v.14, p.303308, 2010. http://dx.doi.org/10.1590/S1415-43662010000300010 AOAC - Official methods of analysis of the Association of Official Analytical Chemists International. 16.ed. Washington: AOAC, v.2, 1997. 1141p.

Belmiro, T. C.; Queiroz, A. J. de M.; Figueiredo, R. M. F. de; Fernandes, T. K. S.; Bezerra, M. C. T. Alterações químicas e físico-químicas em grãos de abóbora durante o armazenamento. Revista Brasileira de Engenharia Agrícola e Ambiental, v.14, p.1000-1007, 2010. http:// dx.doi.org/10.1590/S1415-43662010000900013

Bewley, J. D.; Black, M. Seeds: Physiology of development and germination, 2.ed. New York: Plenum, 1994. 445p. http://dx.doi. org/10.1007/978-1-4899-1002-8

Biaggioni, M. A. M.; Barros, R. E. Teste de acidez graxa como índice de qualidade em arroz. Ciência e Agrotecnologia, v.30, p.679684, 2006. http://dx.doi.org/10.1590/S1413-70542006000400013

Carneiro, S. M. T. P. G.; Romano, E.; Marianowski, T.; Oliveira, J. P.; Garbin, T. H. S.; Araújo, P. M. Ocorrência de Alternaria brassicicola em crambe (Crambea byssinica) no estado do Paraná. Summa Phytopathologica, v.35, p.154, 2009. http://dx.doi. org/10.1590/S0100-54052009000200016

Costa, L. M.; Resende, O.; Gonçalves, D. N.; Sousa, K. A. Qualidade dos frutos de crambe durante o armazenamento. Revista Brasileira de Sementes. v.34, p.293-301, 2012a. http://dx.doi.org/10.1590/ S0101-31222012000200015

Costa, L. M.; Resende, O.; Gonçalves, D. N.; Sousa, K. A.; Sales, J. F.; Donadon, J. R. The influence of drying on the physiological quality of crambe fruits. Acta Scientiarum Agronomy, v.34, p.213-218, 2012b. http://dx.doi.org/10.4025/actasciagron.v34i2.12482
Donadon, J. R.; Resende, O.; Teixeira, S. P.; Santos, J. M.; Moro, F. V. Effect of hot air drying on ultrastructure of crambe seeds. Drying Technology: An International Journal, v.31, p.269-276, 2013. http://dx.doi.org/10.1080/07373937.2012.724490

Eichelberger, L.; Maia, M. S.; Peske, S. T.; Moraes, D. M. Composição química de sementes de azevém em resposta ao retardamento da secagem e ao armazenamento. Pesquisa Agropecuária Brasileira, v.37, p.693-701, 2002. http://dx.doi.org/10.1590/S0100204X2002000500015

Farhoosh, R.; Einafshar, S.; Sharayei, P. The effect of commercial refining steps on the rancidity measures of soybean and canola oils. Food Chemistry, v.115, p.933-938, 2009. http://dx.doi. org/10.1016/j.foodchem.2009.01.035

Faria, R. Q.; Teixeira, I. R.; Devilla, I. A.; Ascheri, D. P. R.; Resende, O. Cinética de secagem de sementes de crambe. Revista Brasileira de Engenharia Agrícola e Ambiental, v.16, p.573-583, 2012. http:// dx.doi.org/10.1590/S1415-43662012000500014

Faroni, L. R. A.; Alencar, E. R.; Paes, J. L.; Costa, A. R.; Roma, R. C. C. Armazenamento de soja em silos tipo bolsa. Engenharia Agrícola, v.29, p.91-100, 2009. http://dx.doi.org/10.1590/S010069162009000100010

Freo, J. D.; Colussi, R.; Biduski, B.; Piccini, D. C.; Elias, M. C.; Gutkoski, L. C. Efeito da umidade de colheita da qualidade tecnológica de grãos de trigo. Revista Brasileira de Armazenamento, v.37, p.16, 2012.

Goes, R. H. T. B.; Souza, K. A.; Patussi, R. A.; Cornello, T. C.; Oliveira, E. R.; Brabes, K. C. S. Degradabilidade in situ dos grãos de crambe, girassol e soja, e de seus coprodutos em ovinos. Acta Scientiarum - Animal Sciences, v.32, p.271-277, 2010.

IAL - Instituto Adolfo Lutz. Métodos físico-químicos para análises de alimentos. São Paulo: Instituto Adolfo Lutz, 2008, 1141p.

José, S. C. B. R.; Salomão, A. N.; Costa, T. S. A.; Silva, J. T. T. T.; Curi, C. C.S. Armazenamento de sementes de girassol em temperaturas subzero: Aspectos fisiológicos e bioquímicos. Revista Brasileira de Sementes, v.32, p.29-38, 2010. http://dx.doi.org/10.1590/S010131222010000400004

Marcos Filho, J. Fisiologia de sementes de plantas cultivadas. Piracicaba: FEALQ, v.12, 2005. 495p.

Monteiro, C. S.; Baldi, M. E.; Miguel, O. G.; Penteado, P. T. P. S.; Haracemiv, S. M. C. Qualidade nutricional e antioxidante do tomate “tipo italiano". Revista Alimentos e Nutrição, v.19, p.25-31, 2008.

Nozaki, V. T.; Munhoz, C. L.; Guimarães, R. C. A.; Hiane, P. A.; Andreu, M. P.; Viana, L. H.; Macedo, M. L. R. Perfil lipídico da polpa e amêndoa da guarirova. Ciência Rural, v.42, p.1518-1523, 2012. http://dx.doi.org/10.1590/S0103-84782012000800030

Oliveira, M. T. R.; Berbert, R. C. P.; Pereira, R. C.; Vieira, H. D.; Thiebaut, J. T. L.; Carlesso, V. O. Qualidade fisiológica e potencial de armazenamento de sementes de carambola. Revista Brasileira de Sementes, v.31, p.236- 244, 2009. http://dx.doi.org/10.1590/ S0101-31222009000200028

Pitol, C. Cultura do crambe. In: Tecnologia e produção: Milho safrinha e culturas de inverno. Maracajú: Fundação MS, 2008. p.85-88.

Pitol, C.; Broch, D. L.; Roscoe, R. Tecnologia e Produção: Crambe 2010. Maracajú: Fundação MS, 2010. 60p.

Ribeiro, R. A.; Queiroz, M. G. M. N.; Alves, V. L.; Prata, E. R. B. A.; Barbosa, E. S.; Santos, E. M.; Mota, B. S. N. Efeitos do tempo de armazenamento sobre as propriedades físico-químicas de óleo de Jatropha curcas (pinhão manso). Revista Brasileira de Oleaginosas e Fibrosas, v.14, p.1-7, 2010. 
Rosseto, R. E.; Santos, R. F.; Bassegio, D.; Secco, D.; Souza, S. N. M.; Chaves, L. I.; Fornasari, C. H. Efeito da secagem na extração de óleos em plantas com potencial energético. Acta Iguazu, v.1, p.69-77, 2012.

Rupollo, G.; Gutkoski, L. C.; Marini, L. J.; Elias, M. C. Sistemas de armazenamento hermético e convencional na conservabilidade de grãos de aveia. Ciência Rural, v.34,p.1715-1722, 2004. http://dx.doi.org/10.1590/S010384782004000600008

Silva, D. J.; Queiroz, A. C. Análise de alimentos (Métodos químicos e biológicos). 3.ed. Viçosa: UFV, 2002. 235p.
Silva, F. S.; Porto, A. G.; Pascuali, L. C.; Silva, F. T. C. Viabilidade do armazenamento de sementes em diferentes embalagens para pequenas propriedades rurais. Revista de Ciências AgroAmbientais, v.8, p.45-56, 2010.

Silva, M. A. P.; Biaggioni, M. A. M.; Sperotto, F. C. S.; Bezerra, P. H. S.; Brandão, F. J. B. Qualidade do óleo de grãos de crambe (Crambe abyssinica Hochst) sob diferentes métodos de secagem. Energia na Agricultura, v.28, p.193-199, 2013.

Souza, A. D. V.; Fávaro, S. P.; Ítavo, L. C. V.; Roscoe, R. Caracterização química de sementes e tortas de pinhão-manso, nabo-forrageiro e crambe. Pesquisa Agropecuária Brasileira, v.44, p.1328-1335, 2009. http://dx.doi.org/10.1590/S0100-204X2009001000017 